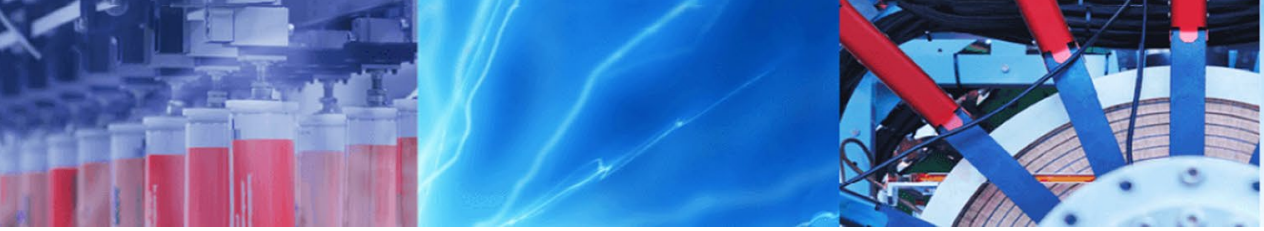

Research Article

\title{
Development of high early strength in concrete incorporating alccofine and non-chloride accelerator
}

\author{
P. Narasimha Reddy ${ }^{1}$ (D) . J. Ahmed Naqash ${ }^{1}$
}

(c) Springer Nature Switzerland AG 2019

\begin{abstract}
Rapid repair and retrofit of existing infrastructures demand durable high early strength materials that not only deliver sufficient strength within a short time after placement but also significantly prolong the maintenance interval. This research paper presents the effects on the mechanical properties and durability of alccofine concrete of the addition of calcium nitrate as a non-chloride hardening accelerator ( $\mathrm{NCHA}$ ). Non-chloride accelerator with concentrations of $0.65 \%$, $0.85 \%$ and $1.05 \%$ by weight of cement, was added to concrete mixes to test the effect on the properties of alccofine concrete which was in turn compared with the reference concrete without NCHA. With addition of accelerator, strength enhancements were observed at an early age due to rapid rate of hydration of $C_{3} A$ and $C_{3} S$ phases. Water absorption and sulphate resistance of alccofine concrete also improved with the non-chloride accelerator. A statistical tool was used to predict the experimental values of compressive strength of concrete. Response surface methodology was adopted to optimize the experimental data set in which regression equation was developed by relating response variable to input variable. This method helped to predict the experimental values within an acceptable error range. The predicted values were cross validated by employing coefficient of determination $\left(R^{2}\right)$ and residual sum of squares (RSS) which showed a good fit. The results of this study showed that the addition of non-chloride hardening accelerator in alccofine concrete significantly improved the mechanical properties as well as durability.
\end{abstract}

Keywords Non-chloride hardening accelerator · Alccofine $\cdot$ Mechanical properties $\cdot$ Response surface method

\section{Introduction}

The most exceedingly used man-made building material in the world is concrete [1]. One of the major drawbacks of the concrete at the early ages is its lesser strength which slows down the construction process [2]. High early strength concrete (HESC) is one of the types in high-performance concretes. It attains high early strength than the conventional concrete [3]. Mainly this type of concrete is used for fast-track paving, precast concrete elements and concrete works in colder regions where it facilitates rapid pace of construction [4].

Generally, fast-track concrete structures need sufficient strength at early ages. In some cases, it is obligatory to accelerate the concrete hardening for removal of formwork such as in precast construction and exigent repair works [5]. There are three ways to improve the early strength of concrete; the first of them is the use of special cement, this cement can reach the predetermined strength in a short time. However, due to its low production and high prices its use in restricted not to be widely used. The second way is improving the construction and maintenance of concrete, such as hot-mix concrete, steam curing treatment methods. However, this method also causes inconvenience in actual industrial production, therefore not been widely adopted. The third way is to use the early strength admixture; practice has proved that this method is the easiest

P. Narasimha Reddy, narasimha_07phd16@nitsri.ac.in; J. Ahmed Naqash, javednaqash@nitsri.net | ${ }^{1}$ Department of Civil Engineering, National Institute of Technology, Hazratbal, Srinagar 190006, Jammu and Kashmir, India.

SN Applied Sciences (2019) 1:755 | https://doi.org/10.1007/s42452-019-0790-z

Received: 3 April 2019 / Accepted: 15 June 2019 / Published online: 20 June 2019

SN Applied Sciences

a SPRINGer Nature journal 
and least costly method, so it has been widely adopted in the construction projects [6].

Recently, chemical admixtures have affected huge changes in cement concrete construction. The mechanism of function of accelerating admixture (non-chloride accelerator) is that it increases the rate of hydration of tricalcium silicate $\left(C_{3} S\right)$ and tricalcium aluminate $\left(C_{3} A\right)$ phases of cement, thereby providing heat evolution and early strength development [7]. It acts as a catalyst in the hydration of tricalcium silicate $\left(C_{3} S\right)$ and tricalcium aluminate $\left(C_{3} A\right)[8]$.

The past researchers have studied the properties of concrete by using different accelerators. Up to now the most effective accelerator has been Calcium chloride, but it promotes the reinforcement corrosion by depletion of passive oxide layer [9]. Due to this, researchers have developed non-chloride accelerators which include thiosulfates, nitrates, nitrites, thiocyanate and formates [10].

A review of non-corrosive and non-chloride accelerating admixtures has been conducted by Dodson. Calcium formate of formula $\mathrm{Ca}(\mathrm{HCOO})_{2}$, is a by-product in the manufacture of polyhydric alcohol, pentaerthritol. It is a powder and has a low solubility of about $15 \%$ in water at room temperature. It is a popular non-chloride chemical that is advocated in practice. Many non-chloride accelerating admixture formulations contain formates. Calcium formate is an accelerator for the hydration of $\mathrm{C}_{3} \mathrm{~S}$; at equal concentration however, $\mathrm{CaCl}_{2}$, is more effective in accelerating the hydration of $C_{3} S$ [11]. Angtadt found that (patented in 1969) Calcium nitrite was the second admixture to meet the requirements of non-chloride accelerator and found that it is a very efficient corrosion inhibitor for concrete-based metals. Justnes has investigated the effect of calcium nitrate on the setting properties of cement and steel corrosion. Calcium nitrate is often used in industry because of its high solubility and cost efficiency. Some studies have shown that the effect of nitrate salts depends on the quantity of belite and aluminium in cement. Triisopropanolamine and triethanolamine are the general grinding chemicals in the cement production process. They are also formulated and used as chemical additives that can improve the mechanical properties of concrete by accelerating the hydration of specific mineral cement-based compounds [12].

The ordinary portland cement which is a major constituent of conventional concrete plays a significantly important role in contributing to the strength properties. But now- a-days cement has become a major source for pollution which compels the researchers to replace cement by some alternative materials which can provide the desirable mechanical and durability properties to concrete as well as address the pollution menace such as dumping of industrial waste.
Alccofine 1203 is proprietary low calcium silicate based mineral additives. Controlled granulation process results in unique particle size distribution. Its latent hydraulic property and pozzolanic reactivity results in enhanced hydration process. Addition of alccofine 1203 improves the packing density of paste component. The production of alccofine is more environmentally friendly compared to the production of OPC, thus producing a more environmentally friendly concrete than the OPC concrete. It has been well documented that alccofine is a very good mineral admixture to be used in improving the properties of the concrete due to its positive effects on its sustainable development and the environment. In the present study, an attempt has been made to study the effects of alccofine as a constant replacement of cement on durability and mechanical properties of concrete and its scope to address environmental pollution caused by industrial by-products. A study was carried out on the effect of non-chloride hardening accelerators on the properties of alccofine concrete in hardened state. It highlights the outcomes of the mechanical properties and durability of different concrete mixes. Hence this paper presents studies of the effect of non-chloride hardening accelerator with addition to alccofine on the properties of concrete and also checks its mechanical properties and durability when high early strength is developed.

\section{Research significance}

The large flow of material driven by concrete global production and consumption and the lack of durability of concrete structures have created large economic, social, and environmental impacts. A new class of repair material that achieves high-early-age strength and durability against typical cracking and delamination failures is urgently needed. This research departs from the traditionally narrow emphasis on only the high or high-early-age compressive strength of concrete repair materials but establishes a detailed understanding and database of the balanced material properties of HESC. The resulting compressive strength and tensile strength characteristics of the new HESC are expected to contribute to fast and durable concrete repairs with a reduced environmental burden with the combination of alccofine and non-chloride accelerator.

\section{Materials}

\subsection{Cement}

Khyber (Brand name) 43 grade of OPC was used and it was tested as per BIS: 8112 specifications [13]. Tables 1 and 2 show the physical and chemical properties of cement. 
Table 1 Physical properties of cement

\begin{tabular}{lll}
\hline Characteristics & Test results & $\begin{array}{l}\text { Requirements as per } \\
\text { IS code }\end{array}$ \\
\hline Grade & 43 & - \\
Specific gravity & 3.10 & - \\
Standard consistency & $30 \%$ & - \\
Fineness modulus $\left(\mathrm{m}^{2} / \mathrm{kg}\right)$ & 310 & Not less than $300 \mathrm{~mm}$ \\
Soundness & 2.50 & Not more than $10 \mathrm{~mm}$ \\
Initial setting time $(\mathrm{min})$ & 94 & Not less than 30 \\
Final setting time $(\mathrm{min})$ & 280 & Not more than 600 \\
\hline
\end{tabular}

\subsection{Aggregates}

Natural river sand was used as a fine aggregate having specific gravity 2.68 and conforming to Zone II. Crushed rocks were used as coarse aggregate and having specific gravity 2.78 , the maximum size of the aggregate was limited to $20 \mathrm{~mm}$ as per BIS:383-1970 specification [14].

\subsection{Alccofine}

Alccofine is an ultra-fine material which is significantly superior to other mineral admixtures which are available in market [15-27]. In this research, the replacement of cement with alccofine was $25 \%$ for all mixes. SEM image of alccofine is shown in Fig. 1. Tables 3 and 4 Show the chemical properties and physical properties of alccofine respectively.

\subsection{Non-chloride hardening accelerator}

A number of inorganic and organic components are available in the present market as non-chloride accelerators. Non-chloride accelerating admixtures include thiosulfates, nitrates, nitrites, thiocyanate and formates [28-42]. In the present research, Master set AC 100 composed primarily of calcium nitrite was used as non-chloride hardening accelerator which conforms to ASTM C494: Type C. The properties of Master set AC 100 are shown in Table 5 .

\section{Fabrication of concrete mixes}

The fabrication of concrete mixes was done as per IS: 10262-2009 specifications to produce M30 grade of concrete [43]. The binder (Cement + Alccofine) to aggregate

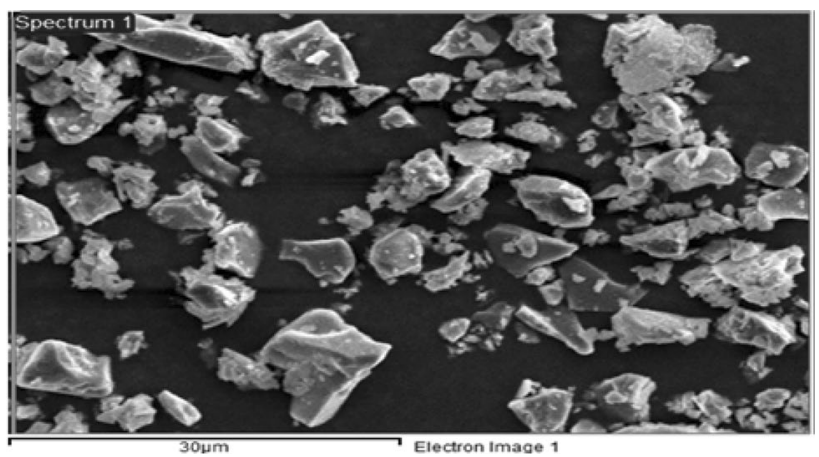

Fig. 1 SEM image of alccofine

Table 3 Chemical composition of Alccofine

\begin{tabular}{llllll}
\hline $\mathrm{CaO}$ & $\mathrm{SiO}_{2}$ & $\mathrm{Al}_{2} \mathrm{O}_{3}$ & $\mathrm{Fe}_{2} \mathrm{O}_{3}$ & $\mathrm{SO}_{3}$ & $\mathrm{MgO}$ \\
\hline $61-64 \%$ & $21-23 \%$ & $5-5.6 \%$ & $3.8-4.4 \%$ & $2-2.4 \%$ & $0.8-1.4 \%$ \\
\hline
\end{tabular}

ratio was obtained as 1:1.40:2.65 for M30 grade concrete (water to binder ratio $=0.45$ ). Alccofine was added as a constant replacement (i.e. 25\%) to all concrete mixes and four mixes in which percentage of chemical admixture was altered were prepared in this research work. Concrete mixes prepared had $328.59 \mathrm{~kg} / \mathrm{m}^{3}$ of cement, $109.53 \mathrm{~kg} / \mathrm{m}^{3}$ of alccofine, $614.59 \mathrm{~kg} / \mathrm{m}^{3}$ of fine aggregate and $1162.53 \mathrm{~kg} / \mathrm{m}^{3}$ of coarse aggregate with waterbinder ratio of 0.45 . Concrete mix (M1) did not contain non-chloride hardening accelerator. From concrete mixes M2 to M4 non-chloride accelerator was added in different proportions as shown in Table 6 and list of experiments for evaluating the mechanical properties and durability are shown in Table 7.

\section{Methodology}

\subsection{Compressive strength}

Compressive strength was evaluated by using cube specimens of size $150 \mathrm{~mm}$ as per code IS: 516-1959 [44]. Total four concrete mixes were casted with varying dosage of non-chloride hardening accelerator and tested under dry conditions. For each mix, three cubes were tested at 3, 7 and 28 days using CTM of $2000 \mathrm{KN}$ capacity at a uniform rate of $5.2 \mathrm{KN} / \mathrm{s}$ by placing the specimen tested
Table 2 Chemical properties of cement

\begin{tabular}{lllllll}
\hline $\mathrm{CaO}$ & $\mathrm{SiO}_{2}$ & $\mathrm{Al}_{2} \mathrm{O}_{3}$ & $\mathrm{Fe}_{2} \mathrm{O}_{3}$ & $\mathrm{SO}_{3}$ & $\mathrm{MgO}$ & Loss on ignition \\
\hline $60-41 \%$ & $20-27 \%$ & $5-32 \%$ & $3-56 \%$ & $3-17 \%$ & $2-46 \%$ & $3-55 \%$ \\
\hline
\end{tabular}


Table 4 Physical properties of alccofine

\begin{tabular}{ll}
\hline Characteristics & Test results \\
\hline Specific gravity & 2.9 \\
Specific surface area $\left(\mathrm{m}^{2} / \mathrm{kg}\right)$ & 1200 \\
Bulk density $\left(\mathrm{kg} / \mathrm{m}^{3}\right)$ & 680 \\
\hline Particle size in micron & \\
\hline $\mathrm{D}_{10}$ & 1.5 \\
$\mathrm{D}_{50}$ & 5 \\
$\mathrm{D}_{90}$ & 9 \\
\hline
\end{tabular}

Table 5 Properties of non-chloride hardening accelerator

\begin{tabular}{llll}
\hline Aspect & Relative density & $\mathrm{P}^{\mathrm{H}}$ & $\begin{array}{l}\text { Chloride ion } \\
\text { content }\end{array}$ \\
\hline $\begin{array}{c}\text { Colourless free } \\
\text { flowing liquid }\end{array}$ & 1.26 at $25^{\circ} \mathrm{C}$ & $>6.0$ at $25^{\circ} \mathrm{C}$ & $<0.2 \%$ \\
\hline
\end{tabular}

at the center of the testing machine. The compressive strength of concrete specimen was evaluated.

\subsection{Split tensile strength}

Split tensile strength tests were carried out on cylinder specimens of size $150 \mathrm{~mm}$ X $300 \mathrm{~mm}$ as per IS 5816-1999 at 7 and 28 days [45]. The cylinder specimen was placed longitudinal to the CTM surfaces and the load was applied until the failure occurred along the vertical diameter of the cylinder. The tensile strength of the cylindrical specimens was calculated.

\subsection{Modulus of rupture}

Modulus of rupture was evaluated on a beam specimen at 7 and 28 days on a CTM as per code IS 516-1959 specification [44]. The modulus of rupture was determined using Eq. 1 below.

$\sigma=\frac{F L}{b d^{2}}$

where: $\sigma=$ modulus of rupture of the concrete specimen in $\mathrm{MPa}, \mathrm{F}=$ failure load $(\mathrm{N}), \mathrm{L}=$ Length of the cylinder $(\mathrm{mm})$, $\mathrm{b}=$ width of the beam specimen $(\mathrm{mm}), \mathrm{d}=$ depth of the beam specimen $(\mathrm{mm})$.

\subsection{Water absorption test}

Water absorption test was carried out on cube specimen of size $150 \mathrm{~mm}$ with varying dosage of non-chloride hardening accelerator. The specimens were taken out from the curing tank at the age of 7 and 28 days. These specimens were dried in an oven at $105^{\circ} \mathrm{C}$ for $24 \mathrm{~h}$ followed by cooling to ambient temperature after which the dry weight was measured. These dried specimens were placed in water at $23^{\circ} \mathrm{C}$ for $48 \mathrm{~h}$ [46]. Specimens were taken out from water and the surface was wiped with a dry cloth before weighing. The water absorption value of the cube specimen was determined as per Eq. 2 below.
Table 6 Mix details of different grades of concrete

Table 7 Summary of tests

\begin{tabular}{lllllll}
\hline Mix & Cement & AF & FA & CA & W/B & NCHA (\%) \\
\hline M1 & 328.59 & 109.53 & 614.59 & 1162.53 & 0.45 & 0 \\
M2 & 328.59 & 109.53 & 614.59 & 1162.53 & 0.45 & 0.65 \\
M3 & 328.59 & 109.53 & 614.59 & 1162.53 & 0.45 & 0.85 \\
M4 & 328.59 & 109.53 & 614.59 & 1162.53 & 0.45 & 1.05 \\
\hline
\end{tabular}

\begin{tabular}{llll}
\hline Test & Specimen dimension $(\mathrm{mm})$ & Age of curing & $\begin{array}{l}\text { No. of } \\
\text { specimen } \\
\text { tested }\end{array}$ \\
\hline Compressive strength & $150 \times 150 \times 150$ & 3.7 and 28 & $4 \times 3 \times 3$ \\
Splitting tensile strength & $150 \times 300$ & 7 and 28 & $4 \times 3 \times 2$ \\
Modulus of rupture & $500 \times 100 \times 100$ & 7 and 28 & $4 \times 3 \times 2$ \\
Water absorption & $150 \times 150 \times 150$ & 28 & $4 \times 3$ \\
Sulphate attack & $150 \times 150 \times 150$ & 28 & $4 \times 3$ \\
\hline
\end{tabular}

Total number of specimens $=108$ 
Water absorption $(\%)=\frac{\text { Saturated weight of the sample }- \text { Dry weight of the sample }}{\text { Dry weight of the sample }}$

\subsection{Resistance against sulphate attack}

The sulphate resistance of concrete was studied by placing the specimens in a sulphate solution. The test was conducted on cubes with and without non-chloride hardening accelerator. The cube specimens of $150 \mathrm{~mm}$ were casted and demoulded after $24 \mathrm{~h}$ followed by curing in water for 28 days [47]. The cubes were taken out from curing tank after 28 days and initial weights were taken. For sulphate attack these cubes were immeresed in sodium sulphate solution having a concentration of $5 \%$ by weight of water. The concentration of sodium sulphate solution was maintained and specimens were taken out from solution at the end of 28 days. The cube surfaces were cleaned with water and kept in normal atmosphere for getting constant weight. The difference between initial and final dry weights indicated the degree of sulphate attack and percentage of Mass loss were calculated by using Eqs. 3 and 4 below.

Strength deterioration factor $(\%)=\frac{\sigma_{1}-\sigma_{2}}{\sigma_{1}} \times 100$

Mass loss $=\frac{W_{1}-W_{2}}{W_{1}} \times 100$

$\sigma_{1}=$ cube compressive strength before immersion in sulphate solution $(\mathrm{MPa}), \sigma_{2}=$ cube compressive strength after immersion in sulphate solution ( $\mathrm{MPa}), \mathrm{W}_{1}=$ weight of cube specimen before immersion in sulphate solution (g), $W_{2}=$ weight of cube specimen after immersion in sulphate solution $(\mathrm{g})$.

\section{Results and discussion}

\subsection{Compressive strength}

In this study, the strength of concrete was evaluated by compression test. Generally in the construction industry, compressive strength of concrete is not only important at later stages but it is equally important at early ages. In this research, a constant replacement of cement with alccofine volume (i.e. $25 \%$ ) was taken as a reference mix and the non-chloride accelerator was added with different proportions. The compressive strength of cubes tested at the age of 3, 7 and 28 days for the water-binder ratio of 0.45 is shown in Fig. 2. It has been recognized that non-chloride hardening accelerator increases the compressive strength of concrete at early ages compared to reference mix. The compressive strength of concrete at early age (3 days) for mixes M2, M3 and M4 were enhanced by $22.34 \%, 35.05 \%$ and $29.02 \%$ compared to reference mix M1. Similar results were also reported by Meagher et al. [5] wherein it was found that chloride free accelerators increased the hydration rate of tricalcium aluminate and tricalcium silicate phases of cement, consequently giving not only heat evolution but also strength enhancement at early ages [48]. At 7 days, ratio of strength improvement was less as compared to 3 days i.e. $5.76 \%, 11.89 \%$ and $6.95 \%$ compared to the reference mix at 7 days. The long term compressive strengths for all concrete mixes were slightly higher than those of reference concrete mix (i.e. Accelerators don't affect the long term properties).

\subsection{Split tensile strength}

Early age cracking may occur because of change in volume due to thermal contraction and shrinkage. Thermal and shrinkage effects induce tensile stresses in concrete. When these stresses are greater than the tensile strength of concrete, which is somewhat low at early ages, it can develop cracks in concrete. Hence it is required to evaluate the tensile strength of concrete at which concrete may crack. The cylindrical specimens were tested to evaluate the split tensile strength of concrete at the age of 7 and 28 days for water binder ratio 0.45 as shown in Fig. 3. From the results,

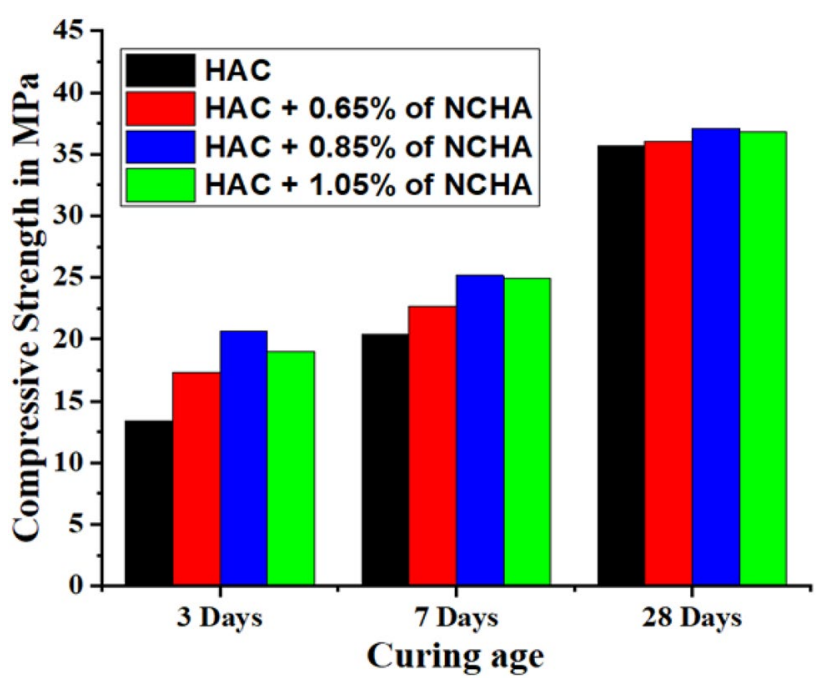

Fig. 2 Compressive strength of alccofine concrete for different proportions of NCHA 
it is clearly observed that the concrete mixes made with non-chloride hardening accelerator showed higher tensile strength values than the reference concrete. The early age split tensile strength ( 7 days) for concrete mixes $\mathrm{M} 2$, M3 and M4 were improved by $9.54 \%, 23.32 \%$ and $16.21 \%$ respectively. The degree of enhancement in split tensile strength for alccofine concrete is slightly higher strengths with non-chloride accelerator at a later age [10].

\subsection{Modulus of rupture}

The modulus of rupture results with and without nonchloride hardening accelerator for concrete mixes with water-binder ratio 0.45 at the age of 7 and 28 days are shown in Fig. 4. In this study, it was observed that reference concrete exhibited less modulus of rupture at given water-binder ratio (i.e. 0.45). The modulus of rupture of concrete at an early age for mixes M2, M3 and M4 were increased by $7.24 \%, 29.03 \%$ and $26.66 \%$ compared to reference alccofine concrete $M 1$. The modulus of rupture of concrete at a later stage for mixes M2, M3 and M4 were almost same compared to reference mix M1. Brook et al. also reported that concrete with non-chloride hardening accelerator showed higher modulus of rupture compared to reference concrete at early age but the modulus of rupture of concrete with non-chloride hardening accelerator at 28th day was the same as that of reference concrete.

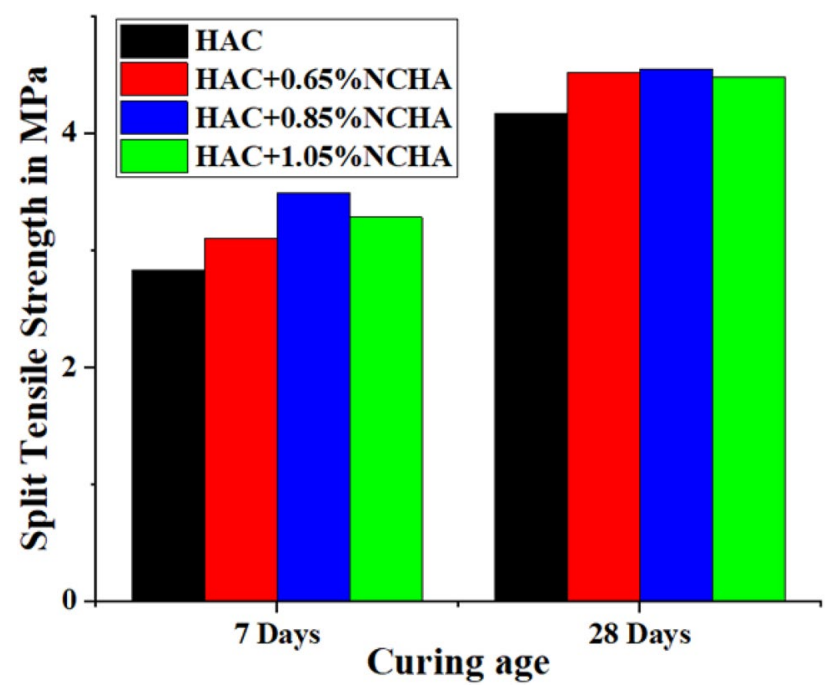

Fig. 3 Split tensile strength of alccofine concrete with different proportion of NCHA

\subsection{Water absorption test}

Water absorption test is one of the most important parameter for finding the durability of concrete. The perforation of ions, water and gases depend on the porosity and microstructure of concrete. Figure 5 shows the results of water absorption test with and without non-chloride hardening accelerator. From the results, it can be seen that reference concrete has more water absorption than that of concrete with non-chloride hardening accelerator. Concrete mixes with the accelerator (i.e. M2, M3 and M4) showed a decrease in the percentage of water absorption values with respect to reference concrete (M1) due to the formation of ettringite at early ages along with alccofine fills the voids between the particles and thus, decreases the permeable voids in the cubes as shown in Fig. 5.

\subsection{Resistance to sulphate attack}

Sulphate attack on the concrete is a chemical disintegration mechanism where sulphate ions attack components of cement paste. The compounds responsible for sulphate attack on concrete are water soluble salts such as alkali (potassium and sodium) and alkali earth (magnesium and calcium) sulphates that are capable of chemically reacting with concrete components. In the present study, the effect of sulphate attack was analyzed on concrete with and without non-chloride hardening accelerator [49].

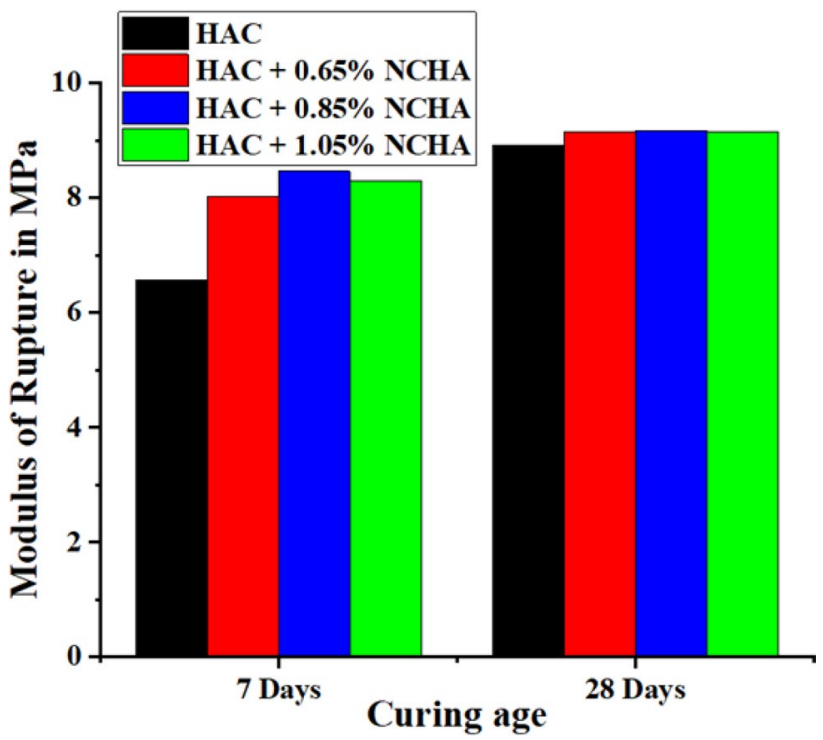

Fig. 4 Modulus of rupture of alccofine concrete with different proportion of NCHA 


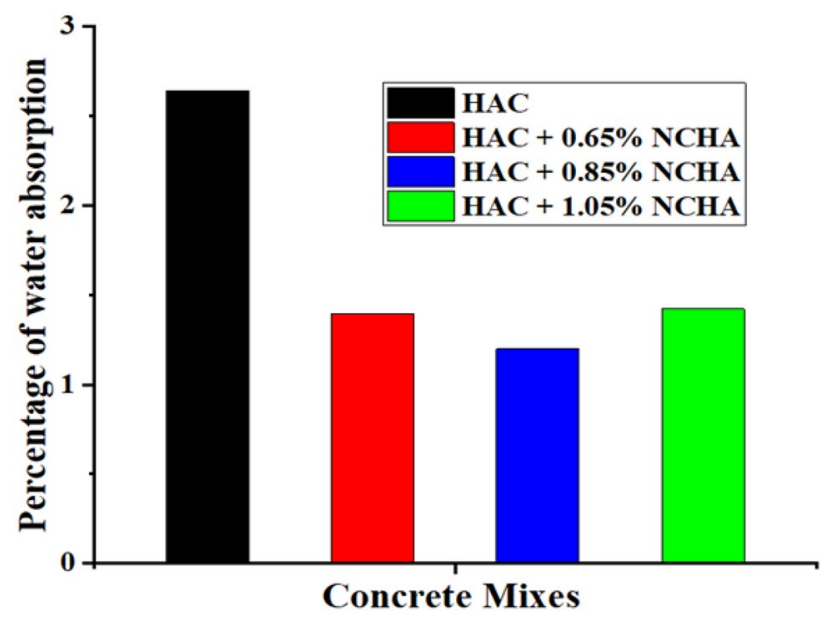

Fig. 5 Percentage of water absorption of alccofine concrete with different proportion of NCHA

The concrete samples were tested for four mixes to find out strength deterioration and mass loss factors. These are shown in Figs. 6 and 7. It was seen that concrete with non-chloride accelerator specimens were less affected than that of reference concrete. From Fig. 7 it is clearly seen that the mass loss decreased with the increment of non-chloride accelerator to concrete. Figure 8 shows the non-chloride accelerator increases the resistance of concrete against sulphate attack.

\section{Design of experiments}

\subsection{Response surface method}

In this research Response Surface Method (RSM) was used for predicting the compressive strength of the concrete. Response surface method is a statistical and mathematical technique which can be used for refining, developing and optimizing processes in the research and industrial field [25]. It can evaluate the effects of one or more variables and their interactions on one or more response variables. It can be represented by Eq. 5, which relates the variables $£$ and responses $y$ for a specified system [50].

$y=f\left(£_{1}, £_{2}, £_{3} \ldots \ldots . . f_{k}\right)+\varepsilon$

where $f_{1}, f_{2}, f_{3} \ldots f_{\mathrm{k}}$ are the input variables, $\mathrm{y}$ is the response, $f$ represents approximate response function and $\varepsilon$ denotes the statistical error.In this research, the second order polynomial was used instead of the linear polynomial to evaluate response from input variables as shown in Eq. 6.

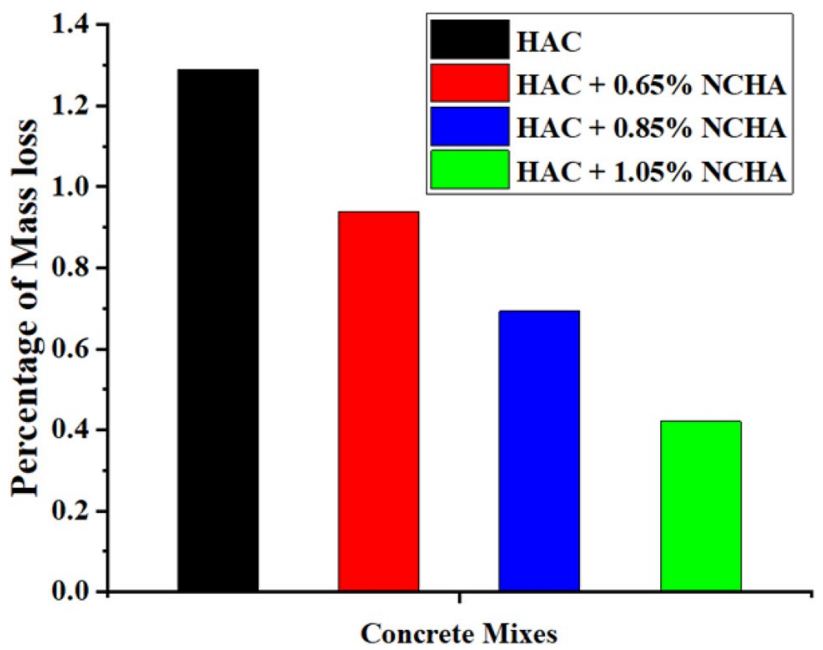

Fig. 6 Percentage of mass loss of alccofine concrete with different proportion of NCHA

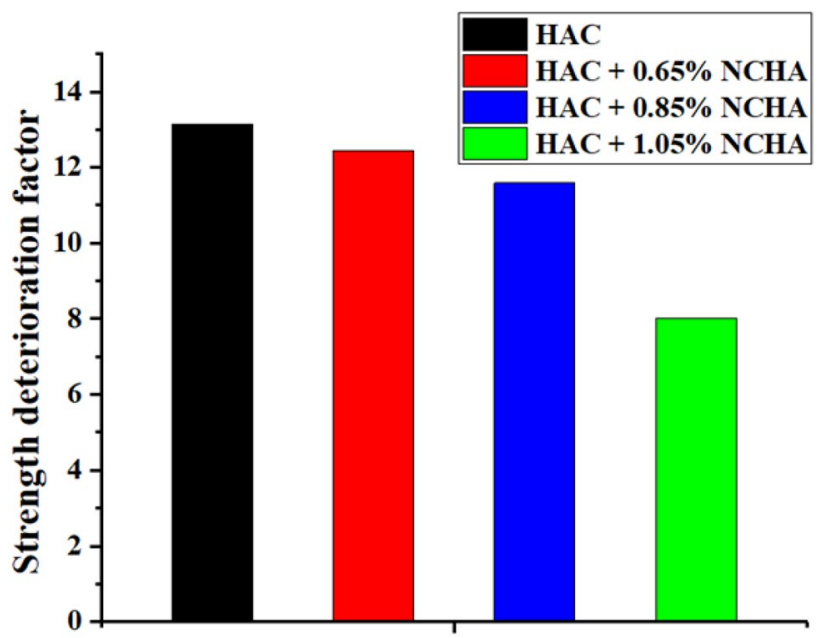

Concrete Mixes

Fig. 7 Strength deterioration factor of alccofine concrete with different proportion of NCHA

Surface Plot of Compressive strength vs \%NCHA, Curing age

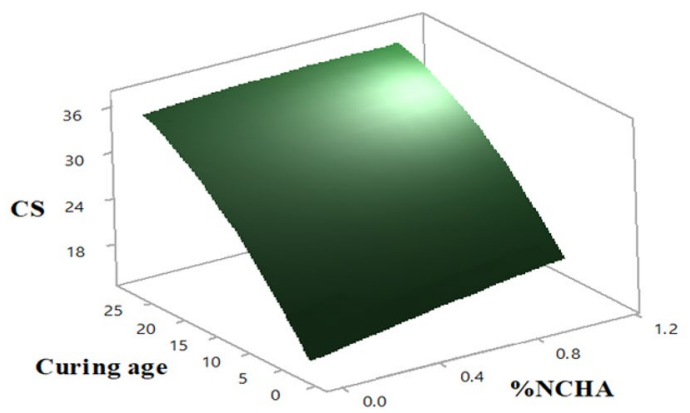

Fig. 8 Response surface plot for "compressive strength" versus "\%NCHA", "curing age" 
$\mathrm{y}=\beta_{\mathrm{o}}+\sum_{i=1}^{\mathrm{k}} \beta_{\mathrm{i}} £_{\mathrm{i}}+\sum_{i=k}^{\mathrm{k}} \beta_{\mathrm{ii}} £_{\mathrm{ii}}^{2}+\sum_{i=1}^{\mathrm{k}} \sum_{j=1, j \neq 1}^{\mathrm{k}} \beta_{\mathrm{ij}} £_{\mathrm{i}} £_{\mathrm{j}}+\varepsilon$

where $y=$ response, $\beta=$ coefficient, $£=$ factor and $\varepsilon=$ error. $\beta_{\mathrm{o}}, \beta_{\mathrm{i}}, \beta_{\mathrm{ii}}$ and $\beta_{\mathrm{ij}}$ are the regression coefficients for intercept, linear, quadratic and interaction terms respectively, and $£_{1}$ and $£_{\mathrm{j}}$ are the input variables

In the present research, two independent variables were "dosage of Non-chloride hardening accelerator" and "Curing age" and the dependent response variable was compressive strength of concrete. By using this method which employs the regression analysis, response surface and residuals plots of the variables were evaluated in addition to main effect.

In this study, MINITAB was used to obtain the values of the coefficients by virtue of regression analysis for $95 \%$ confidence levels $(a=0.05)$ wherein the general Eq. 8 takes the following form Eq. 7.

$\mathrm{Z}=\mathrm{A}+\mathrm{BX}+\mathrm{CY}+\mathrm{DX} \mathrm{X}^{2}+\mathrm{EY}^{2}+\mathrm{FXY}$

where $Z=$ compressive strength of concrete, $X=$ percentage of non-chloride accelerator, $Y=$ curing age, The coefficient values evaluated were $A=9.878, B=6.57, C=1.421$, $\mathrm{D}=-1.22, \mathrm{E}=-0.01792$ and $\mathrm{F}=-0.1563$.

Table 8 shows the predicted and experimental values of compressive strength along with residual error. The regression model obtained from response surface analysis consisted compressive strength $(Z)$ versus the curing age $(Y)$ and the \%NCHA (X) as shown in Fig. 8. The percentage of error less than $5 \%$ was observed for the predicted response surface plot thereby showing 95\% confidence level [51].

\subsection{Residual plots}

The graph between fitted and residual values shows the closeness of predicted compressive strength to experimentally observed data. The points near to the reference line in Fig. 9 designate less error and the points far from the reference line show more error. The error observed in Fig. 9 was found to be within acceptable range of tolerance with two residual values very close to the reference line. In the range of 0-0.4 and 0.4-0.8 the observed residual values were 2 and 3 respectively. Similarly, under the reference line 2 and 3 residual values were found to be in the range 0 to -0.4 and -0.4 to -0.8 respectively.

\subsection{Effect of \%NCHA and curing age on compressive strength of concrete (Main effects)}

The effects of "\%NCHA" and "Curing age" when plotted with reference to mean compressive strength were
Table 8 Predicted and experimental values by using regression analysis

\begin{tabular}{lrllr}
\hline $\mathrm{X}(\%)$ & $\mathrm{Y}(\mathrm{d})$ & $\begin{array}{l}\text { Z experi- } \\
\text { mental } \\
(\mathrm{MPa})\end{array}$ & Z predicted (MPa) & Residual (MPa) \\
\hline 0.65 & 28 & 35.917 & 36.5206 & -0.603584 \\
1.05 & 28 & 36.716 & 36.5718 & 0.144218 \\
0.00 & 28 & 35.674 & 35.6057 & 0.068293 \\
0.65 & 3 & 17.295 & 17.4324 & -0.137417 \\
1.05 & 3 & 18.964 & 19.0463 & -0.082262 \\
0.00 & 3 & 13.426 & 13.9782 & -0.552239 \\
0.65 & 7 & 21.672 & 21.9919 & -0.319854 \\
1.05 & 7 & 22.637 & 23.3557 & -0.718675 \\
0.85 & 28 & 36.986 & 36.5949 & 0.391074 \\
0.85 & 3 & 19.060 & 18.2881 & 0.771917 \\
0.85 & 7 & 23.182 & 22.7225 & 0.459492 \\
0.00 & 7 & 19.523 & 18.9440 & 0.579036 \\
\hline
\end{tabular}

indicated by the magnitude of slope wherein larger values of slope indicated higher effect on the parameter considered (i.e. compressive strength) and vice versa. It was observed from the slope of "\%NCHA - Mean compressive strength plot" that the strength enhanced up to $0.85 \%$ NCHA followed by decrease the same when computed at $1.05 \%$. The plot of Compressive strength-curing age was seen with a steeper slope compared to "\%NCHA-Mean compressive strength plot" which clearly indicated that curing age had a greater role in the compressive strength development that increased further of the 7 days as shown in Fig. 10.

\section{Cross-validation or performance evalution}

Cross-validation is a technique to determine the perfection of the performance of the predictive model (i.e. in the residual sum of squares and the coefficient of determination) and it can be used when the amount of data is limited and the response $Y$ is a quadratic or linear regression model with a function $P_{\mathrm{X}}^{\top}(\mathrm{X})=\left[\mathrm{X}_{1} \mathrm{X}_{2} \ldots \ldots \mathrm{X}_{1}^{2} \mathrm{X}_{2}^{2} \ldots.\right][52]$.

\subsection{Coefficient of determination (COD) $\left(\mathbf{R}^{2}\right)$}

The determination coefficient is a statistic that indicates the rate of change in the quantity of the response variable that is predictable from the explanatory variable as explained in the regression model [53] using Eqs. 8 and 9 below.

$\mathrm{R}^{2}=1-\frac{\sum_{\mathrm{k}=1}^{n}\left(\mathrm{Y}_{\mathrm{k}}-\hat{\mathrm{Y}}_{\mathrm{k}}\right)^{2}}{\sum_{\mathrm{k}=1}^{n}\left(\mathrm{Y}_{\mathrm{k}}-\hat{Y}\right)^{2}}$ 
Fig. 9 Residual plot for compressive strength

\section{Residual Plots for CS}
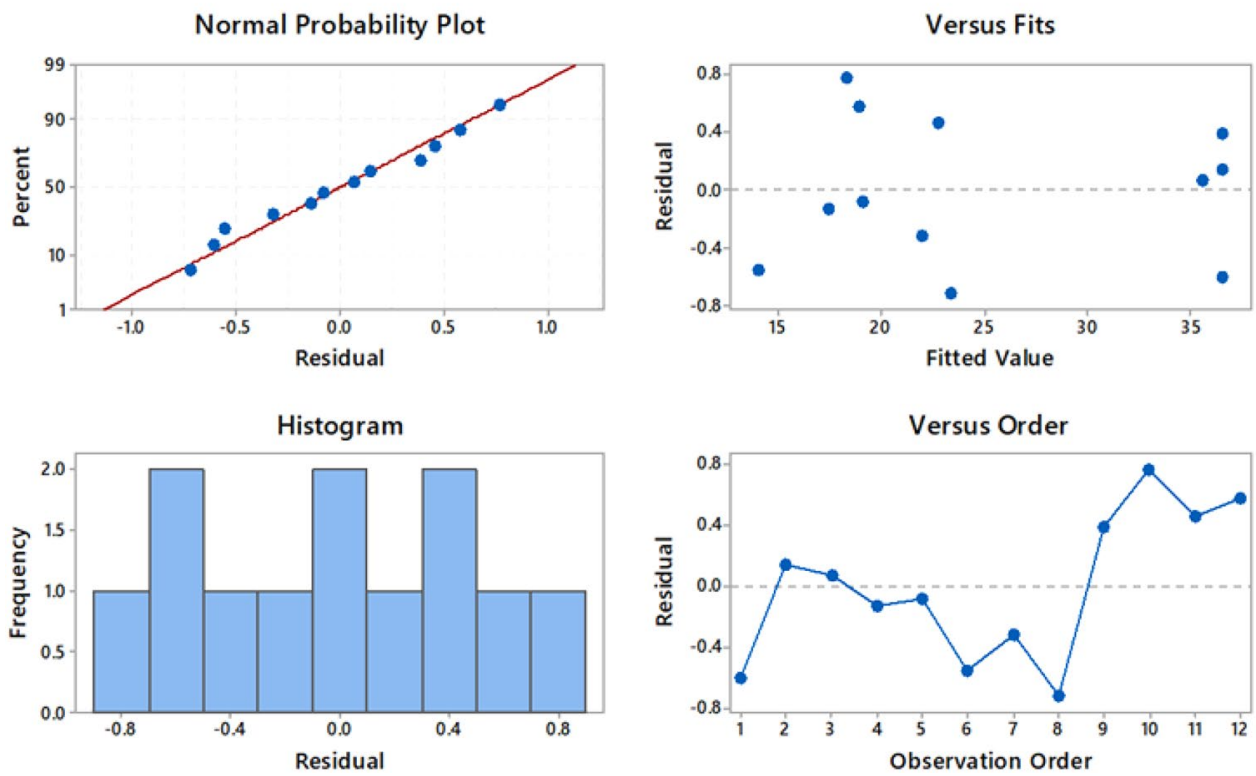

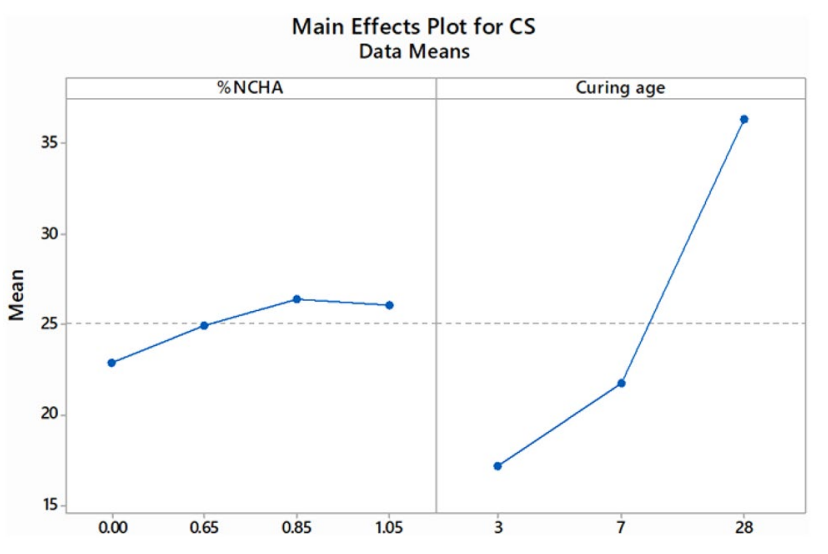

Fig. 10 Main effects plot for compressive strength

$\hat{Y}=\frac{1}{n} \sum_{\mathrm{k}=1}^{n}\left(Y_{\mathrm{k}}\right)$

where $\hat{Y}_{\mathrm{k}}=$ predicted values, $Y_{\mathrm{k}}=$ experimental values.

The coefficient of determination value obtained in this study was with 0.9968 an acceptable range i.e. $0.0032 \%$. The predicted and actual compressive strength values obtained by the regression equation are shown in Table 9 . From this cross-validation we concluded that there is no deviation between the predicted and actual values.

\subsection{Residual sum of squares (RSS)}

Residual sum of squares also called as a summed square of residuals. It is a well-known parameter to calculate the discrepancy between the estimation model and data set using below Eq. 10. The smaller residual sum of square values shows a goodness of fit of the model to the data [54].

Residual sum of squares $=\sum_{\mathrm{k}=1}^{n}\left(\mathrm{Y}_{\mathrm{k}}-\hat{Y}_{\mathrm{k}}\right)^{2}$

The residual sum of square value obtained was 2.634 as shown in Table 9, thus indicating a good fit.

\section{Conclusion}

In this research, the effect of non-chloride hardening accelerator on mechanical properties and durability of alccofine concrete was studied. From the results, it is concluded that non-chloride accelerator enhanced compressive strength of the concrete at an early age due to increase in the rate of hydration of $\mathrm{C}_{3} \mathrm{~A}$ and $\mathrm{C}_{3} \mathrm{~S}$ phases of cement. The use of accelerator didn't influence the mechanical properties of concrete at a later age thereby resulting in same values for all mixes. Water absorption values were less with alccofine in the combination of non-chloride accelerator compared to reference concrete due to micro particle size of alccofine which made the concrete more denser, more compacted and also improved the pore structure of the concrete which helped to improve strength as well as reduces the water absorption percentage. Concrete with accelerator was also found to have increased the resistance against sulphate attack. The experimental data was modelled by using the response surface method in Minitab software which employed regression analysis for 
Table 9 Response surface model for cross validation

\begin{tabular}{lllcccc}
\hline$Y_{\mathrm{k}}$ & $\hat{Y}_{K}$ & $\hat{Y}$ & $Y_{\mathrm{k}}-\hat{Y}_{\mathrm{k}}$ & $Y_{\mathrm{k}}-\hat{Y}$ & $\mathrm{R}^{2}$ & $\mathrm{RSS}$ \\
\hline 35.917 & 36.52058 & 25.08767 & -0.60358 & 10.82933 & & \\
36.716 & 36.57178 & 25.08767 & 0.144218 & 11.62833 & & \\
35.674 & 35.60571 & 25.08767 & 0.068293 & 10.58633 & & \\
17.295 & 17.43242 & 25.08767 & -0.13742 & -7.79267 & & \\
18.964 & 19.04626 & 25.08767 & -0.08226 & -6.12367 & & \\
13.426 & 13.97824 & 25.08767 & -0.55224 & -11.6617 & 0.9968 & 2.634 \\
21.672 & 21.99185 & 25.08767 & -0.31985 & -3.41567 & & \\
22.637 & 23.35568 & 25.08767 & -0.71868 & -2.45067 & & \\
36.986 & 36.59493 & 25.08767 & 0.391074 & 11.89833 & & \\
19.060 & 18.28808 & 25.08767 & 0.771917 & -6.02767 & & \\
23.182 & 22.72251 & 25.08767 & 0.459492 & -1.90567 & & \\
19.523 & 18.94396 & 25.08767 & 0.579036 & -5.56467 & & \\
\hline
\end{tabular}

predicting the values where in the error were formed to be tolerance acceptable range ( $95 \%$ confidence level) thus implying reliable prediction. The cross validation of data by evaluation of coefficient of determination and residual sum of squares conformed the same.

Acknowledgements The authors acknowledge the National Institute of Technology, Srinagar, (Jammu and Srinagar), providing laboratory testing facility. The authors are further thankful for the Ambuja Cement Ltd, Goa and BASF chemicals, Mumbai for providing the required material.

\section{Compliance with ethical standards}

Conflict of interest The author(s) declare that they have no conflict of interest.

\section{References}

1. Saxena SK, Kumar M, Singh NB (2018) Effect of Alccofine powder on the properties of Pond fly ash based Geopolymer mortar under different conditions. Environ Technol Innov 9:232-242. https://doi.org/10.1016/j.eti.2017.12.010

2. Richardson A (2007) Strength development of plain concrete compared to concrete with a non-chloride accelerating admixture. Struct Surv 25:418-423. https://doi.org/10.1108/02630 800710838455

3. Bhavikatti MA, Karjinni V (2012) Combined effect of hardening accelerator and method of curing in the strength development of pavement concrete. Int J Civ Struct Eng 2:1060-1069. https://doi.org/10.6088/ijcser.00202040005

4. Bhavikatti MA (2012) Effect of non-chloride hardening accelerator on the compressive and flexural strengths at early and later age of pavement concrete produced with pozzolana cement. Int J Eng Technol Nat Sci 6:59-63

5. Meagher T, Shanahan N, Buidens D, Riding KA, Zayed A (2015) Effects of chloride and chloride-free accelerators combined with typical admixtures on the early-age cracking risk of concrete repair slabs. Constr Build Mater 94:270-279. https://doi. org/10.1016/j.conbuildmat.2015.07.003
6. Aïtcin PC, Flatt RJ (2015) Science and technology of concrete admixtures. https://doi.org/10.1016/c2015-0-00150-2

7. Xu S, Chen Z, Zhang B, Yu J, Zhang F, Evans DG (2009) Facile preparation of pure $\mathrm{CaAl}$-layered double hydroxides and their application as a hardening accelerator in concrete. Chem Eng J 155:881-885. https://doi.org/10.1016/j.cej.2009.08.003

8. Naqash JA, Lone IH, Majid A, Gayas B, Hussaini I, Hassan M (2015) Accelerating admixture "rapidite"-its effect on properties of concrete. Int J Civ Eng Technol 6:58-65

9. Myrdal R (2007) Accelerating admixtures for concrete, SINTEF report, ISBN: 978-82-536-0989-8

10. Malhotra VM (1996) Concrete admixtures handbook, pp 410 517. https://doi.org/10.1016/b978-081551373-5.50011-8

11. Dodson V (1990) Concrete admixtures. Van Nostrand Reinhold, New York, pp 34-38

12. Bentur A, Technlon IIT (1975) Ceramic, I.I.T. Technlon, T. City, Printed in the United States 5:597-606. https://doi. org $/ 10.1039 / \mathrm{b} 507188 \mathrm{~g}$

13. BIS 8112 (2013) Ordinary Portland cement, 43 grade specification. Bureau of Indian Standards, New Delhi

14. IS: 383-1970 Specifications for coarse and fine aggregates from natural sources for concrete. New Delhi, India: Bureau of Indian Standards

15. Jindal BB, Singhal D, Sharma SK, Ashish DK, Parveen (2017) Improving compressive strength of low calcium fly ash geopolymer concrete with alccofine. Adv Concr Constr 5(1):17-29

16. Jindal BB, Singhal D, Sharma SK (2017) Suitability of ambient cured alccofine added low-calcium fly ash-based geopolymer concrete. Ind J Sci Technol 10(12):1-10

17. Narender Reddy A, Meena T (2017) A comprehensive overview on performance of nano-silica concrete. Int J Pharm Technol 9(1):5518-5529

18. Narender Reddy A, Meena T (2017) Behavior of ternary blended concrete under compression. Int J Civil Eng Technol 8(4):2089-2097

19. Jindal BB, Anand A, Badal A (2016) Development of high strength fly ash based geopolymer concrete with alccofine, Special Issue -AETM'16, IOSR J Mech Civ Eng 55-58

20. Bode Venkata Kavyateja, J. Guru Jawahar and C. Sashidhar, Investigation on ternary blended self compacting concrete using fly ash and alccofine, International Journal of Recent Technology and Engineering, Vol. 7, No. 5S2, 2019, pp. 447-451

21. Reddy PN, Naqash JA (2019) Durability and mechanical properties of concrete modified with ultra-fine slag. Int J Innov Technol Explor Eng 8(5):230-234 
22. Reddy PN, Naqash JA (2019) Strength prediction of high early strength concrete by artificial intelligence. Int J Eng Adv Technol 8(3):330-334

23. Ramanathan $P$, Baskar I, Muthupriya P, Venkatasubramani $R$ (2013) Performance of self-compacting concrete containing different mineral admixtures. KSCE J Civ Eng 17(2):465-472

24. Reddy AN, Meena T (2018) Study on effect of colloidal nano silica blended concrete under compression. Int J Eng Technol 7(10):210-213

25. Jindal BB, Singhal D, Sharma SK, Parveen (2017) Prediction of mechanical properties of alccofine activated low calcium fly ash based geopolymer concrete. ARPN J Eng Appl Sci 12(9):3022-3031

26. Jindal BB, Parveen, Singhal D, Goyal A (2018) Predicting relationship between mechanical properties of low calcium fly ashbased geopolymer concrete. Trans Ind Ceram Soc 76(4):258-265

27. Reddy AN, Meena T (2018) A study on compressive behavior of ternary blended concrete incorporating alccofine. Mater Today Proc 5:11356-11363. https://doi.org/10.1016/j.matpr 2018.02.102

28. Shideler JJ (1952) Calciumchloride inconcrete. J Am Concr Inst 23(7):537-559

29. Heikal M (2004) Effect of calcium formate as an accelerator on the physicochemical and mechanical properties of pozzolanic cement pastes. Cem Concr Res 34:1051-1056. https://doi. org/10.1016/j.cemconres.2003.11.015

30. Rixom R, Mailvaganam N (1999) Chemical admixtures for concrete, 3rd edn. Routledge, New York

31. Cement Admixtures Association (2012) Admixture technical sheet-ATS 4 accelerating admixtures. [Online]. http://www. admixtures.org.uk/downloads/ATS >4Acceleratingadmixtures. pdf

32. Aggoun S, Cheikh-Zouaoui M, Chikh N, Duval R (2008) Effect of some admixtures on the setting time and strength evolution of cement pastes at early ages. Constr Build Mater 22(2):106-110

33. Justnes $\mathrm{H}$ (2005) Chloride-free accelerators for concrete setting and hardening, vol SP-229-1. ACI Special Publication, pp 3-16

34. Justnes $\mathrm{H}$ (2001) Calcium nitrate as a multifunctional concrete admixture. In: SINTEF technology and society, concrete, 2001

35. Rosskopf PA, Linton FJ, Peppler RB (1975) Effect of various accelerating chemical admixtures on setting and strength development of concrete. ASTM Int 3:322-330

36. Angstadt RL, Spring S, Hurley FR (1696) Accelerator for Portland cement, US Patent 3,427,175, 1969

37. Balonis M (2010) The influence of inorganic chemical accelerators and corrosion inhibitors on the mineralogy of hydrated Portland cement systems, University of Aberdeen, 2010

38. Abdelrazig BE, Bonner DG, Nowell DV, Dransfield JM, Egan PJ (1990) Effects of accelerating admixtures on cement hydration. In: Vazquez E (ed) Admixtures for concrete improvement of properties. Chapman and Hall, Barcelona, pp 120-136
39. Myrdal R (2007) Accelerating admixtures for concrete. SINTRF Building and Infrastructure, Trondheim

40. RILEM Technical Committee 119-TCE (1998) RILEM TCE1: adiabatic and semiadiabatic calorimetry to determine the temperature increase in concrete due to hydration heat of the cement. Mater Struct 30(10):451-464

41. Rosenberg AM (1964) Study of the mechanism through which calcium chloride accelerates the set of Portland cement. J Am Concr Inst 61(10):1261-1268

42. Justnes H, Vanparijs ATF, Van Gemert D (2002) Porosity and diffusivity of concrete with long-term compressive strength increase due to addition of the set accelerator calcium nitrate. In: 9th international conference on durability of building materials and components, 2002, pp 1-10

43. BIS (2009) 10262, Guidelines for Concrete Mix Design Proportioning, Bureau of Indian Standards. 2009

44. IS 516 (1959) Method of tests for strength of concrete

45. BIS 5816 (1999) Split tensile strength of concrete. New Delhi, India: Bureau of Indian Standards

46. C642-06 (2006) Standard test method for density, absorption and voids in hardened concrete. ASTM Standards

47. Indian standard code of practice for plain and reinforced concrete. IS: 456-2000: Bureau of Indian Standards, New Delhi

48. Shanahan N, Sedaghat A, Zayed A (2016) Effect of cement mineralogy on the effectiveness of chloride-based accelerator. Cement Concr Compos 73:226-234. https://doi.org/10.1016/j. cemconcomp.2016.07.015

49. Mohan A, Mini KM (2018) Strength and durability studies of SCC incorporating silica fume and ultra fine GGBS. Constr Build Mater 171:919-928. https://doi.org/10.1016/j.conbuildma t.2018.03.186

50. A. Barbora, K.U.C. Erova, Statistical analysis of real time PCR, (2012)

51. PhD Thesis Arun Kumar M B

52. Vu-Bac N, Rafiee R, Zhuang X, Lahmer T, Rabczuk T (2015) Uncertainty quantification for multiscale modeling of polymer nanocomposites with correlated parameters. Compos B Eng 68:446-464. https://doi.org/10.1016/j.compositesb.2014.09.008

53. Vu-Bac N, Silani M, Lahmer T, Zhuang X, RabczukT (2015) A unified framework for stochastic predictions of mechanical properties of polymeric nanocomposites. https://doi.org/10.1016/j. commatsci.2014.04.066

54. Hasan MM, Kabir A (2011) Prediction of compressive strength of concrete from early age test result, vol 9, pp 978-984. https ://doi.org/10.13140/rg.2.1.3270.7684

Publisher's Note Springer Nature remains neutral with regard to jurisdictional claims in published maps and institutional affiliations. 